\title{
Direito de Autor. Apanhado Histórico. Legislação Brasileira de Caráter Interno ${ }^{(*)}$
}

\author{
Conselheiro Prof. Antônio Chaves \\ Presidente do Instituto Interamericano \\ de Direito de Autor (IIDA)
}

\begin{abstract}
SUMARIO: 1. Sistema de privilégios. 2. Em 1710, a primeira lei especifica. 3. Evolução da legislação de caráter interno até a Lei no 5.988. 4. A Lei no 5.988, de 14-12-1973. Projetos. Elaboração. Vantagens e inconvenientes. 5. A Comissão Revisora da Lei no 5.988/73.
\end{abstract}

\section{Sistema de privilégios}

A antigüidade não tinha qualquer noção do direito de autor, tal como o concebemos hoje em dia.

Sem embargo da alta estima em que era tida a produção intelectual na Grécia, prestando governo e povo as maiores homenagens aos seus dramaturgos, poetas, filósofos, cientistas, compositores, artistas plásticos, concedendo prêmios aos vencedores de concursos e coroando-os em praça pública, reservando-lhes elevados cargos administrativos, os produtos da inteligência e da arte não eram considerados mais do que uma «coisa», que pertencia ao seu autor.

O plágio era, sem dúvida, praticado e reconhecido, mas não encontrava outra sanção senão a verbação do prejudicado e a condenação da opinião pública.

Roma já dispunha de uma rudimentar indústria livreira, pois havia organizações que se incumbiam de fornecer numerosas cópias manuscritas (bibliópolas), mediante licença dos autores, valendo-se principalmente do trabalho de escravos ou de religiosos. As cópias, em papiros, uma vez corrigidas, eram entregues aos «glutinators», que costuravam as folhas colocando-as em condições de serem vendidas.

Citam-se alguns raros casos de transação, como o mencionado por Juvenal de Stacio, que morreria de fome se não tivesse vendido sua tragédia «Agavé». Segundo Terêncio, teriam os edis comprado de $\mathrm{Me}$ nandro sua comédia «O Eunuco», e Plauto era acusado de só pensar em dinheiro, indifirente ao sucesso ou ao fracasso de suas obras.

(*) Conferência de Abertura do Curso Especializado sobre Direito de Autor, promovido pelo Ministério da Cultura, através do CNDA, com a cooperação da OMPI (Genebra) e SUISA (Zurich), de 16 a 26-04-1985, no Salão do Ministério das Relações Exteriores, em Brasília. 
A proteção legislativa da criação intelectual constitui fenômeno moderno, pois remonta a menos de três séculos. Antes dessa época, apesar de o espírito e a inteligência do homem terem produzido obras imortais, ninguém se preocupou em lhes ligar a noção de prerrogativa cuja violação devia ser reprimida por lei.

Com a descoberta da imprensa e a conseqüente facilidade na obtenção da reprodução dos trabalhos literários, surgiu também a concorrência das edições abusivas. Daí o interesse em reprimí-las, pois o autor, que antes podia pelo menos exercer uma fiscalização material sobre a multiplicação dos exemplares das obras, decorrente da posse do manuscrito original, passou a perdê-la, uma vez que cada possuidor de uma cópia impressa podia, com facilidade, obter duplicatas.

$\mathrm{Na}$ Renascença surgiu o sistema de se conceder a determinados impressores o privilégio da publicação das obras mais célebres. CUNHA GONCCALVES aponta como a mais antiga a outorgada em 1495, pela República de Veneza, ao impressor Aldo, para uma edição das obras de Aristóteles. Mas PIOLA CASELLI revela serem anteriores os concedidos pela mesma República, em 1469, a Giovanni da Spira, em 1486 a Marco Antonio Sabellico e em 1492, a Pier Francesco da Ravenna.

Os privilégios não decorriam de prerrogativas que os editores tivessem adquirido dos escritores, vindo apenas a título de compensação.

Autores e editores não reivindicavam um verdadeiro direito: contentavam-se com a garantia de que, os primeiros a sua produção intelectual, e os segundos, o ingente capital que empregavam na indústria, não sofreriam concorrência, o que conseguiam com o sistema de monopólio.

Tais predecessores do negócio editorial - comenta OSMAN LINS - eximiam-se de conferir ao autor qualquer parcela dos lucros, por mínima que fosse: empalmavam-nos a título de compensar as despesas da publicação.

«Sua magnamidade se exprimia no desinteresse pela glória, que concediam toda ao escritor, apenas reservando para si o ouro. Lamenta-se por isto Marcial, dizendo que sem um mecenas o poeta não teria fontes de subsistência e ver-se-ia obrigado a escolher entre as ocupações de delator, de falsa testemunha ou de ajudante nos banhos públicos».

Em decorrência dos privilégios muitas obras antigas ficavam de propriedade exclusiva dos editores, que as legavam aos seus sucessores, mormente depois que por sucessivas prorrogações dos prazos eles se tornariam perpétuos no reinado de Luís XIV.

Com o desenvolvimento da indústria editorial em conseqüência das idéias novas que se haviam de propagar pela Reforma e pela Revolução Francesa, começou a cair em desagrado tal regime, ao mesmo tempo que os escritores se inteiraram da importância da sua contri- 
buição, e procuravam uma melhor recompensa de seus esforços e de seus sacrifícios.

\section{Em 1\%10, a primeira lei específica}

Coube à Grã-Bretanha, com a célebre lei da Rainha Ana, de 14-04-1710, sancionando o «copyright», a glória de ter sido a vanguardeira da regulamentação legal da matéria, "para encorajar a ciência e garantir a propriedade dos livros àqueles que são seus legítimos proprietários; «para encorajar os homens instruídos a compor e escrever obras úteis», mediante o reconhecimento de um direito exclusivo de reprodução sobre as obras por eles criadas.

Foi seguida pela Dinamarca, que por decreto de 07-01-1741 veio a reconhecer o direito de autor.

Como os privilégios dos soberanos franceses fossem concedidos exclusivamente aos editores e impressores de Paris, contra estes se insurgiram os das outras cidades da França. E foi na luta entre os dois grupos que pela primeira vez se ouviu proclamar os direitos do autor, idéia formulada em 1725 por LUIS D'HÉRICOURT, advogado dos livreiros de Paris, e depois repetida por outros, com tal eficácia que em 1777 o Conselho de Estado, em duas resoluções, votava a abolição dos privilégios perpétuos.

Inaugura-se, com isso, - encarece OSMAN LINS, a conceituação moderna, segundo a qual o autor - e não mais o editor - detém a propriedade da obra literária.

«Sua importância, todavia, faz-se sentir na Europa inteira ao longo de todo o século XVII; multiplicam-se os panfletos debatendo o assunto e processos cada vez mais numerosos chegam aos Tribunais. Os escritores já não admitem ser espoliados. Mas só em julho de 1793, a França, que em janeiro promulgara decreto consagrando o direito exclusivo dos autores, no sentido de permitir a encenação de seus textos dramáticos, estende a proteção a todas as outras obras literárias. $O$ incremento da atividade legislativa nesse setor ocorre na primeira metade do seculo passado.»

Com efeito, a Assembléia constituinte francesa, chamada a firmar uma nova ordem social, ao mesmo tempo que abolia todos os privilégios, reconheceu, pelo deputado LE CHAPELIER, que a obra dos autores devia ser reconhecida como. « la plus sacrée, la plus légitime, la plus personelle des propriétés».

A lei de 13-19.01.1791 atribuiria a mesma prerrogativa unicamente aos autores dramáticos durante a sua vida e aos seus herdeiros por cinco anos após a morte: publicadas ou não, só poderiam ser representadas em qualquer teatro público, com o consentimento formal e por escrito dos autores os seus herdeiros ou cessionários, sob pena de confisco do produto total das representações em proveito dos mesmos. 
A Lei de 19-24.07.1793, ampliou esse direito:

"Art. 19. Os autores de escritos de toda espécie, os compositores de música, os arquitetos, os escultores, os pintores, os desenhistas, os que gravarem quadros ou desenhos, gozarão durante toda a sua vida, do direito exclusivo de vender, fazer vender, distribuir suas obras no território da República, e ceder-lhe a propriedade, no todo ou em parte».

Sete artigos apenas de uma lei incipiente. Mas proteção segura aos autores e artistas da terra em que mais floresceram e se irradiaram para o mundo inteiro, durante 163 anos, servindo ainda de inspiração à legislação específica de todos os demais países.

\section{Evolução das legislação brasileira de caráter interno até a Lei 5.988}

Enquanto colônia o Brasil estava subordinado à legislação portuguesa, que pela Constituição de 1838 , art. $23, \S 4^{\circ}$, garantiu aos inventores a propriedade das suas descobertas e aos escritores a de seus escritos, pelo tempo e na forma que a lei determinasse.

A Constituição do Império (Carta de Lei de 25-03-1824) não contém qualquer referência ao direito de autor de obra literária ou artística o que não deixa de ser estranho, porquanto o art. 179 já ressalvara:

«26. Os inventores terão a propriedade de suas descobertas ou das suas produções. A lei lhes assegurará um privilégio exclusivo temporário, ou lhes remunerará um ressarcimento da perda que hajam de sofrer pela vulgarização».

Nem o Ato Adicional (Lei de 12-08-1834), nem a Carta de 10-11-1937 mencionam o direito de autor.

Mas as Constituições de 24-02-1891, art. 72, § 26, a de 16-07-1934, art. 113, al. 20, a de 10-09-1946, art. 141, § 19, a de 24-01-1967, art. 150, $\S 25$ e a Emenda Constitucional $n^{\circ} 1$, de 17-10-1969, consideraram-no expressamente, dispondo esta última:

Art. 153, § 25. «Aos autores de obras literárias, artísticas e científicas pertence o direito exclusivo de utilizá-las. Esse direito é transmissivel por herança, pelo tempo que a lei fixar».

O texto de 1946, art. 141, $\S 19$, assegurava o «direito exclusivo de reproduzí-las». A conceituação de «utilização» é muito mais ampla do que «reprodução», visto ser esta de caráter corpóreo e uma das espécies daquela.

Proclamada a Independência, o primeiro diploma que contém uma referência à matéria é dos mais nobres e reverenciados: a própria Lei de 11-08-1827, que "Crêa dous Cursos de sciencias jurídicas e sociaes, uma na cidade de São Paulo e outro na cidade de Olinda».

Depois de especificar as matérias a serem ensinadas «no espaço de cinco anos, e em nove cadeiras», de determinar que para a regência 
das mesmas nomeasse o Governo «nove Lentes proprietários», com o ordenado que tivessem os Desembargadores das Relações, e gozassem das mesmas honras, e cinco substitutos, vencendo o ordenado anual $800 \$ 000$, consignava:

«Art. 7\%. Os Lentes farão a escolha dos compendios da sua profissão, ou os arranjarão, não existindo já feitos, com tanto que as doutrinas estejam de accôrdo com o systema jurado pela nação. Estes compendios, depois de approvados pela Congregação, servirão interinamente; submettendo-se porém a approvação da Assembléia Geral, e o Governo fará imprimir e fornecer às escolas, competindo aos seus autores o privilégio exclusivo da obra por dez annos».

O Código Criminal, Lei de 16-12-1830, estatuiu pioneiramente na América Latina:

«Art. 261. Imprimir, gravar, lithographar ou introduzir quaesquer escriptos ou estampas, que tiverem sido feitos, compostos ou traduzidos por cidadãos brazileiros, em quanto estes viverem, dez anos depois da sua morte, se deixarem herdeiros.

Penas. Perdas de todos os exemplares para o autor ou traductor, ou seus herdeiros, ou, na falta d'eles, do seu valor e outro, e de multa igual ao tresdobro do valor dos exemplares.

Se os escriptos ou estampas pertencerem a corporações, a prohibição de imprimir, gravar, lithographar ou introduzir durará somente por espaço de des annos».

Em 1875 - lembra BRUNO JORGE HAMMES - JOSÉ DE ALENCAR propôs um projeto ao Parlamento com o objetivo de conseguir a proteção aos autores, projeto esse que não chegou a ser debatido. "Uma segunda proposição mereceu ao menos uma tomada de conhecimento, mais não passou disto.»

O Código Penal da República dos Estados Unidos do Brasil, promulgado pelo Decreto $n^{\circ}$ 847, de 11-10-1890, regulou a matéria, no Capítulo V, «Dos Crimes contra a Propriedade Litteraria, Artística, Industrial e Comercial», Seção I, «da Violação dos Direios da Propriedade Literária e Artistica», nos arts. 342-350.

A Lei $n^{\circ}$ 496, de 01-08-1898, denominada MEDEIROS E ALBUQUERQUE, em homenagem ao seu autor, estendeu a duração, de dez, para cincoenta anos a contar de $1^{\circ}$ de janeiro do ano em que a obra fosse publicada.

Vedou, no art. 5, alterações não autorizadas, mesmo de obras caídas em domínio público ou que não gozassem de proteção legal (art. $21, \S 2^{\circ}$ ); no art. $7^{\circ}$, decretou a impenhorabilidade do direito autoral de reprodução; no art. 24, estabeleceu proteção ao direito autoral de nominação; no art. 17 , estatuiu que a alienação do objeto de arte não compreendia o direito autoral de reprodução; no art. $4^{\circ}, \S 1^{\circ}$, dispôs 
sobre a ineficácia do direito autoral de reprodução além de 30 anos; no art. $4^{\circ} \S 2^{\circ}$, legou ao autor o poder de, a cada edição, emendar, alterar ou rever a obra.

Foi complementada pela Lei $\mathrm{n}^{\circ} 2.577$, de 17-01-1912, que reconheceu o direito de autor às obras publicadas em países estrangeiros, qualquer que seja a nacionalidade de seus autores.

Anteriormente ao Código Civil registram-se alguns decretos, promulgando ou aprovando convenções internacionais.

Esse Estatuto, Lei $n^{\circ}$ 3.071, de 01-01-1916, além de, no art. 48, III classificar o direito de autor entre os bens móveis; e de fixar, no art. $178, \S 10, n^{0}$ VII, em cinco anos a prescrição da ação civil por ofensa a direitos de autor; contado o prazo da data da contrafação, regulou a matéria aos art. 649-673, sob a epígrafe «Da Propriedade Literária, Científica e Artística», nos arts. 1346-1358, «Da Edição», e arts. 1359-1362, «Da Representação Dramática».

Ao redor do princípio constitucional, e dos dispositivos do $\mathrm{CC}$, à medida em que foram se acelerando os meios de comunicação, de que se aproveitou a difusão das obras literárias, musicais e artísticas, foi se desdobrando também a atividade do legislador, acumulando, ao sabor das necessidades do momento, numerosíssima legislação complementar, a ponto de se contarem às centenas os textos legislativos referentes à matéria enumerados em nosso Direito Autoral de Radiodifusão, S. Paulo, Ed. Rev. Tribunais, 1952, págs. 22 e segs., e atualizada pelo Des. MILTON SEBASTIÃO BARBOSA, na Exposição de Motivos de seu Anteprojeto.

O Decreto $\mathrm{n}^{\circ}$ 4.790, de 02-01-1924 definiu os direitos autorais.

O Decreto $\mathrm{n}^{\circ}$ 5.492, de 16-07-1928, Lei Getúlio Vargas, regulou a organização das empresas de diversão e a locação de serviços teatrais, procurou pôr em dia os nossos obsoletos textos anteriores com os progressos decorrentes da cinematografia, da radiodifusão, da televisão e da indústria do disco, tendo sido parcialmente revogado pelo decreto $\mathrm{n}^{9}$ 20.493, de 24-01-1946 (art. 133).

O Decreto n: 18.526, de 10-12-1928, Regulamento Gilberto de Andrade da organização das empresas de diversões e da locação de serviços teatrais, foi parcialmente revogado pelo decreto $\mathrm{n}^{\circ} 20.493$, de 24-01-1946 (art. 133) e pelo decreto $n^{\circ}$ 1.023, de 17-05-1962 (art. 38).

A Consolidação das Leis Penaes de VICENTE PIRAGIBE, aprovada e adotada pelo Decreto $\mathrm{n}^{\circ} 22.213$, de 14-02-1932, aproveitando os arts. $1^{\circ}, 19,20,21,23,24,25,26$, parágrafo único da Lei $\mathrm{n}^{\circ} 496$, o art. $2^{\circ}$ do Decreto $n^{\circ} 4.790$, de 02-01-1924, e o art. 649, $\S 1^{\circ}$ do Código Civil, no Capítulo V, «Dos Crimes contra a Propriedade Literária, Artística, Industrial e Comercial», do Título XII, «Dos Crimes contra a Propriedade Pública e Particular», do Livro $\Pi$, regulou extensamente a matéria nos arts. 342-350. 
O Decreto-Lei $\mathrm{n}^{0}$ 21.111, de 01-03-1932, que deu normatividade à execução dos serviços de radiocomunicação em todo o território nacional, previstos no Decreto-Lei $n^{0}$ 20.047, de 27-05-1931, dispôs no art. 35:

« 1 $1^{\circ}$ - A irradiação de quaisquer assuntos ou trabalhos já divulgados ou não por outro meio, deverá respeitar os direitos autorais e ser igualmente precedida da indicação dos nomes dos autores».

O Código Penal vigente, Decreto-Lei $\mathrm{n}^{\circ}$ 2.848, de 07-12-1940, regula a matéria em apenas três dispositivos, arts. 184-186, sob a epígrafe: dos crimes contra a propriedade intelectual.

Os arts. 184 e 186 foram objeto de profunda e importantíssima alteração pela Lei $n^{\circ}$ 6.895, de 17-12-1980.

O aludido Decreto $n^{\circ} 20.493$ aprovou o Regulamento do Serviço de Censura e Diversões Públicas do Departamento Federal de Segurança Pública, ampliado pelo Decreto 1.023, de 17-05-1962 (arts. 79-92, 105 e 106 e 113-132), que passou a denominar Departamento de Polícia Federal.

A Lei n’ 2.415, de 09-02-1955, que dispõe sobre a autorga de licença autoral para a realização de representações e execuções públicas e para transmissões pelo rádio ou televisão, acrescentou pertencer ao autor, o direito de outorgar licença, em todo o território nacional, para a realização de representações, execuções públicas e teletransmissões pelo rádio e pela televisão, direito esse que tanto pode ser exercido pelo autor, pessoalmente, como pelas sociedades legalmente constituidas para defesa de direitos autorais às quais for filiado.

Como o Decreto $\mathrm{n}^{\circ}$ 18.527, de 10-12-1928 limitava a proteção e fiscalização do direito de autor exclusivamente ao Distrito Federal, seus dispositivos foram alterados e revogados pelo Decreto 1.023, de 17-05-1962, que estende aos Estados e Territórios a legislação em vigor naquele Distrito, em parte revogado Decreto-lei 980, de 20-10-1969, art. $4^{\circ}$

É constituido de 39 artigos.

O fundamental é o 1: «Qualquer espetáculo público (representações, execuções, irradiações, funções esportivas e beneficentes etc.) realizado em teatro, cinema, estações de rádio e televisão, circo, parque, cassino, clube, associações recreativas ou esportivas, salões de dependências adequadas, depende de aprovação do respectivo programa pelo Serviço de Censura de Diversões Públicas (S.C.D.P.) no Distrito Federal e pela autoridade policial nos Estados e Territórios, seja o espetáculo ou função promovido por pessoa física ou jurídica, ou por entidade de organização comercial ou de organização civil.»

O dispositivo seguinte enumera as representações, execuções, projeções, funções, espetáculos públicos, etc., que «ficam expressamente dependentes da condição prévia, indispensável sob qualquer alegação». 
Seguem normas relativas aos pedidos necessários à realização de espetáculo promovido por particular, ou grupo de pessoas, por artistas ou corpo de artistas (art. $3^{\circ}$ ), ao programa, sua aprovação e anúncios (arts. 4\%-14); às obrigações dos empresários, presidentes ou diretores de companhias teatrais, cinemas, cassinos, circos, etc. (art. 15) ; às sociedades para a defesa de direitos autorais (16-17); à imposição de penalidades, recursos, multas, defesas, etc. (18-36), merecendo referência.

«Art. 37. Na aplicação dos preceitos deste Decreto e dos demais dispositivos regulamentares, que regem a mesma espécie, ter-se-á sempre em vista a sua adequação com os princípios das Convenções Internacionais sobre direitos de autor, ratificadas pelo Brasil.»

De mera complementação o art. 38, que revoga as disposições em contrário, especialmente os preceitos do Decreto $\mathrm{n}^{\circ}$ 18.527, de 10-12-1928 que ao mesmo Decreto $n^{\circ} 1.023$ se contraponham, e o art. 39.

A Lei $\mathrm{n}^{\circ}$ 4.944, de 06-04-1966, que dispõe sobre a proteção a artistas, produtores de fonogramas e organismos de radiodifusão (Direitos Conexos aos Direitos de Autor), foi regulamentada pelo Decreto $\mathrm{n}^{\circ}$ 61.123, de 18-08-1967.

\section{A Lei $n^{o}$ 5.988, de 14-12-1973. Projetos, elaboração Vantagens e inconvenientes}

Não correspondendo mais os dispositivos do $\mathrm{CC}$, promulgados no começo do século, sem embargo de sua atualização através de numerosas leis e decretos que sempre colocaram nossa legislação entre as mais progressistas, às imposições decorrentes dos modernos meios de comunicação, foi sentida a necessidade de facilitar seu manuseio através de um texto único.

O processo - frisa HENRY JESSEN - teve início «como resultante de dois fatores fundamentais: a necessidade de consolidar as disposições esparsas sobre a matéria, de um lado, e do outro as campanhas de descrédito movidas ou fomentadas por determinados usuários da obra musical contra as sociedades arrecadadoras e a que não faltavam, comumente, os protestos certos compositores insatisfeitos, enredados - quantas vezes por ignorância e ingenuidade - nas acerbas críticas às suas entidades autorais».

O então Presidente da República JÂNIO QUADROS incumbiu em 1961 seu Procurador Geral da República Prof. CANUTO MENDES DE ALMEIDA de constituir um Grupo de Trabalho para estudo do problema.

Nela representando a União Brasileira de Compositores (UBC) o compositor HUMBERTO TELXEIRA, - que, ocupando uma cadeira na Câmara dos Deputados, havia apresentado o Projeto $\mathrm{n}^{\circ}$ 238, de 1975, - ofereceu um substitutivo, 238-B, nesse mesmo ano de 1961, 
que consolidou os textos legislativos anteriores introduzindo algumas modificações.

Seus 73 artigos, que chegaram a ser aprovados pela Câmara, entrando em tramitação pelo Senado Federal eram divididos em 11 Capitulos, versando respectivamente:

I. Definição e Caracteriisticas (arts. 1?-10);

II. Registro (11-24);

III. Domínio Público - Exceções (25-28);

IV. Publicação e Reprodução (29-35)'

V. Violação (36-40);

VI. Preços e Cobrança (41-44);

VII. Programas (45-48);

VIII. Reprodução Fonográfica (49-53);

IX. Entidades Autorais (54-60);

X. Publicação Impressa (61-73);

$\mathrm{XI}$. Disposições Gerais (64-73).

Por proposta do Deputado MAURfCIO TOLEDO em 1971 foi criada na Câmara dos Deputados a Comissão Especial para Revisão e Atualização da Legislação sobre os Direitos Autorais, tendo como relator o Deputado ALTAIR CHAGAS.

Surgiu em seguida a idéia ambiciosa de dotar o País de um verdadeiro Código de Direito de Autor e Direitos Conexos, tendo sido, por iniciativa do Ministro da Justiça Senador MEM DE SÁ, designado o desembargador MILTON SEBASTIÃO BARBOSA para refundir e atualizar a legislação brasileira relativa à matéria.

O resultado de seu labor, o Anteprojeto de Código do Direito do Autor e Direitos Conexos, constituído de 351 artigos, procedido por minuciosa exposição de motivos, foi publicado em separata do Diário Oficial da União de 16-06-1967, distribuída aos Tribunais, Conselhos da Ordem dos Advogados do Brasil, Institutos dos Advogados, Faculdades de Direito, entidades e pessoas interessadas.

«Buscando leis e decretos, portarias e semelhantes, «diz expressivamente sua justificação — » «chegamos à conclusão de que em nosso país são tantos os órgãos, são tantas as medidas que visam, direta ou indiretamente, proteger os autores, os artistas, a obra do espírito, que, por extravagante irrisão, a proteção se torna ineficaz, se dilui no seio de tantas providências oriundas, indiscutivelmente, das melhores intenções. A unificação do sistema estatal protetor e capaz de solucionar divergências é um imperativo da realidade brasileira. $\mathrm{E}$ leis, disposições de largo alcance social, são totalmente ineficazes quando não se cuida de cominar, com propriedade, as sanções correspondentes aos interesses defendidos. Normas punitivas 
em branco contribuem para que a lei nem sequer intimide. Com despesas menores, reunindo num só órgão todos aqueles que devem, nos diversos campos da administração, cuidar da matéria versada no anteprojeto, poderá o Estado, com maior realismo, enfrentar e, sem falso otimismo, solucionar problemas que há longos anos vêm perturbando largos setores da vida nacional, como, para exemplificar, o da cobrança de direitos de autor, relativos a execução pública, foco rotineiro de incompreensões entre o autor e o usuário de obras utilizadas, com indisfarçáveis prejuízos para a cultura.»

O Ministro da Justiça, Luiz Antonio da Gama e Silva nomeou, em maio de 1967, uma comissão encarregada de proceder à revisão daquele trabalho.

De um lado, animados de espírito francamente reformador, aquele magistrado e o autor destas linhas, refundindo completamente a contribuição preliminar, deram-lhe maior organicidade e estrutura mais rigorosa, procurando incorporar nos 198 a que reduziram os 351 artigos primitivos, as mais recentes conquistas das legislações avançadas.

De outro lado, o antigo Ministro do Supremo Tribunal Federal professor CANDIDO MOTA FILHO, mais conservador, apresentou um substitutivo de 89 artigos, que sem qualquer inovação, limitou-se a uma consolidação parcial dos dispositivos mais importantes do $\mathrm{CC}$ e das leis esparsas posteriores.

O Projeto BARBOSA-CHAVES era dividido em três partes. A primeira, DIREITO DO AUTOR (arts. 1-60), compunha-se de três títulos, subdivididos em Capítulos: Generalidades (A Obra, Autoria); Atributos (Disposição Preliminar, Do Direito Moral, Utilizando sob Forma Corpórea e Utilização sob Forma Incorpórea).

A segunda, TRANSMISSÃO (arts. 61 a 119), incluía um Título relativo à Transmissão Causa Mortis, e outro, Transmissão Inter Vivos, que, em Capítulos sucessivos, cuidava da Cessão de Direitos (Peculiaridades, Direitos e Deveres) e das seguintes Obras Literária, Musical, Artística, Científica e Técnico-Científica: Gráfica, Fonográfica ou Fonovisual, Dramática, de Arte Plástica, Fotográfica, Jornalística ou Periodística, do Artista Intérprete ou Executante, Cinematográfica, Radiofônica ou Audiovisual, e da Resolução e Revogação dos Contratos.

A terceira, finalmente, DEFESA (arts. 120 a 198), constituída por um único Título: órgão, Medidas Cautelares e Sanções, era formada. por seis Capítulos: Sociedades de Defesa dos Direitos do Autor e Conexos, Conselho Nacional de Direitos do Autor e Direitos Conexos CONDAC, Registro, Medidas Cautelares, Das Sanções: Violações Crimes - Procedimentos, e Disposições Finais e Transitórias.

O Projeto, como se vê, enfrentava os problemas relativos à determinação da autoria, dos atributos do direito de autor, do direito moral, da utilização da obra seja sob forma corpórea como sob a in- 
corpórea. Dedicava atenção especial à cessão de direitos, consignado os requisitos que deve conter o respectivo instrumento, esmiuçando os direitos e deveres que competem aos autores e aos empresários em geral, para, depois, distinguir as diversas modalidades das obras, a cada uma consagrar tratamento orgânico.

Não se animando a optar pelo trabalho da maioria, o Governo, incumbiu de elaborar um novo projeto o Prof. JOSÉ CARLOS MOREIRA ALVES, então Procurador Geral da República e hoje membro dos mais brilhantes do Supremo Tribunal Federal. Pressionado pela urgência reduziu o sonhado projeto de Código ao projeto de uma simples Lei, que, em sua redação final, foi publicado no Diário do Congresso Nacional de 28-11-1973.

Foram apresentadas 233 emendas, a primeira das quais, pelo Senador FRANCO MONTORO, que passava à Mesa a fim de que constasse dos arquivos para a consulta dos eventuais interessados, o Projeto BARBOSA-CHAVES, mesmo Diário, 08-11-1976. Mas o prazo exíguo de 10 dias mal permitiu a aprovação de algumas poucas, mais urgentes.

Nele baseado, mas dele desviando-se em pontos fundamentais, resultou a Lei 5.988, de 14-12-1973, cujos 134 artigos são divididos em Nove Títulos.

O I, Disposições Preliminares (arts. 1-5) contém uma série de definições nem sempre satisfatórias.

O II, Das Obras Intelectuais (arts. 6-20), subdivide-se em três Capítulos, cuidando, respectivamente, Das Obras Intelectuais Protegidas, Da Autoria das Obras Intelectuais e Do Registro das mesmas.

O III, Dos Direitos do Autor (21-56), compôe-se de cinco Capítulos: Disposições Preliminares, Dos Direitos Morais do Autor, Dos Direitos Patrimoniais do Autor e de sua Duração, Das Limitações aos Direitos do Autor, e Da Cessão dos Direitos do Autor.

O IV, Da Utilização de Obras Intelectuais (57-93), tem oito (um dos quais, o relativo à utilização de fonogramas, composto de um único, vetado e, depois inserido pela Lei $\mathrm{n}^{\circ} 6.800$, de 25-06-1980, de conteúdo diferente): Da Edição, Da Representação e Execução, Da Utilização de Obra de Arte Plástica, da Utilização de Obra Fotográfica, Da Utilização de Obra Cinematográfica, Da Utilização da Obra Publicada em Diários ou Periódicos e Da Utilização de Obras Pertencentes ao Domínio Público.

O Título V, Dos Direitos Conexos (94-102), abrange cinco Capítulos: Disposição Preliminar, Dos Direitos dos Artistas Intérpretes ou Executantes, e do Produtores de Fonogramas. Dos Direitos das Empresas de Radiodifusão, Do Direito de Arena e Da Duração dos Direitos Conexos. 
O VI, cuida Das Associações de Titulares de Direitos do Autor e dos que lhe são Conexos (arts. 103-115).

O VII, Do Conselho Nacional de Direito Autoral (116-120).

O VIII, Das Sanções à Violação dos Direitos do Autor e Direitos que lhes são Conexos (arts. 121-131) compreende três capitulos: Disposição Preliminar, Das Sanções Civis e Administrativas e da Prescrição.

Finalmente, o IX é formado por três Disposições Finais e Transitórias.

Sem embargo de numerosas imperfeições é um marco histórico, apresentando soluções próprias, algumas corajosas, retiradas do referido Projeto, possibilitando um esforço para moralizar a proteção, a arrecadação, a cobrança e a distribuição dos direitos autorais, até então à mercê de algumas entidades particulares que multiplicavam as despesas de sua manutenção e pouco distribuiam, submetendo-as a um rigoroso controle de despesa, e à fiscalização exercida pelo órgão encarregado de reger a política oficial a respeito da matéria: o Conselho Nacional de Direito Autoral.

Deveria suplantar os obsoletos dispositivos do $\mathrm{CC}$, ainda sob a epigrafe «Da propriedade literária, científica e artística», e de dezenas de diplomas legais que procuravam acomodá-los às conquistas do cinema, da radiodifusão e da televisão. Longe, porém, de consolidá-los para substituí-los, modernizando-os, ressalva o art. 134 «a legislação especial que com ela for compatível».

O texto oferece sem dúvida pontos positivos, ao lado de outros menos felizes.

Entre os primeiros, registra-se:

1. a exigência de que toda e qualquer cessão de direito de autor seja feita por escrito;

2. o estabelecimento de uma perfeita diferenciação entre o direito moral, amplamente protegido, e o pecuniário;

3 . a regulamentação separada dos direitos de edição, de representação, de execução, das obras de arte plástica, da obra fotográfica e cinematográfica;

4. a regulamentação, num texto único, tanto dos direitos de autor, como dos artistas intérpretes e executantes, evitando distorções e pontos de atrito possiveis quando as duas atividades sejam submetidas a diplomas legais diferenciados;

5. clara proteção aos projetos de arquitetura e semelhantes, mesmo em caso de introdução de modificações por parte do proprietário da construção.

6. criação de um órgão de fiscalização, consulta e assistência, no que diz respeito a direitos do autor e direitos que lhe são conexos, o Conselho Nacional de Direito Autoral (CNDA); 
7. concentração da percepção num Escritório Central de Arrecadação e Distribuição (ECAD), constituído pelas próprias Sociedades;

8. fiscalização rigorosa da gestão das Associações de Direitos Autorais, pelo CNDA, com poderes inclusive de intervenção;

9. Regulamentação do domínio público remunerado.

Entre os aspectos negativos:

1. a sistematização, a estrutura mesmo da lei não são boas, encontrando-se disposições sob título que não lhes são adequados;

2. definições inexatas;

3. ter admitido um confuso «Direito de arena», concedido, não ao atleta, mas «à entidade a que esteja vinculado», de autorizar ou proibir, a fixação, transmissão ou retransmissão, por quaisquer meios ou processos, de espetáculo desportivo público, com entrada paga, ressalvando ainda convenção em contrário, para permitir que $20 \%$ do preço da autorização sejam distribuídos em partes iguais aos atletas participantes do espetáculo, matéria, evidentemente, relativa ao direito à própria imagem, e não ao direito de autor;

4. não ter consolidado os textos legais anteriores, para poder revogar os diplomas legais antigos, que, ao contrário, manteve em vigor, levantando por essa forma incerteza de quais os dispositivos que estão e quais os que não estão mais em vigor.

Da repercussão da nova Lei no exterior dão uma idéia as considerações expendidas por CARLOS MOUCHET, consagrado especialista argentino, na reunião do Conselho Panamericano da Confédération des Sociétés d'Auteurs et Compositeurs (CISAC) de Caracas, em junho de 1974, reproduzidas, em parte, pelo Correio Brasiliense de 21 de agosto do mesmo ano.

Deu-lhe o significado de «um acontecimento de grande repercussão, não só por regular a matéria em país tão importante, como é a República Federativa do Brasil, como pelo significado da admissão de critérios jurídicos que merecem ser examinados pelas sociedades de autores e pelos juristas que se dedicam a esta disciplina do direito.»

Mas tão importante como o conteúdo da nova lei assinala as suas ausências:

«Acertos - sua sistemática e estrutura, em geral, é clara.

A existência de um conjunto de definições no art. 14, facilita sua interpretação e aplicação.

Com o melhor dos critérios, o direito de autor não nasce do registro da obra, mas da sua criação, como reconhecimento de sua carac- 
terística de direito humano. O registro se estabelece apenas como uma medida administrativa para segurança do direito dos autores (art. 17). O registro é gratuito (art. 19).

Como representante dos interesses culturais da comunidade, compete ao Estado, através do Conselho Nacional de Direito Autoral, velar pela integridade e fidelidade das obras caídas em domínio publico (art. 25 , inciso 2). É, pode-se dizer, a contrapartida da faculdade de arrecadar direitos pelo uso das obras em domínio público (domínio público remunerado).

Relativamente à obra arquitetônica considera uma boa solução reconhecer-se ao autor do projeto, no exercício do «direito moral», a faculdade de repudiar a paternidade da mesma, se no decorrer da execução do projeto, ou depois, se introduzem modificações sem o seu consentimento (art. 27).

E explicitamente afirmado o princípio da independência das formas de utilização das obras intelectuais (art. 35), o que é de grande importância prática em matéria de autorização de uso e transferências de direitos.

Com justiça, é estabelecido que a realização da obra, em cumprimento de um contrato de trabalho ou de um dever funcional, não importa na perda dos direitos de autor; embora não seja partidário da solução de atribuí-los, em partes iguais ao dador do trabalho e ao dependente, sem distinguir entre direitos morais e direitos patrimoniais. Parece mais lógico reservar sempre ao autor o direito moral e distribuir os resultados econômicos conforme o que preserva o acordo contratual, ou o estatuto da função pública, ou de trabalho.

Introduz-se a instituição do direito de mais valia (droit de suite) relativo à alienação de obras artísticas ou manuscritos (art. 39), o que se funda em critério de justiça.

Quanto à duração dos direitos de autor, estes se transmitem vitaliciamente aos ascendentes, filhos e esposa; e durante 60 anos a outros sucessores.

Aplaude francamente esta solução, que se ajusta à tendência atual de ampliar os prazos de proteção "post-mortem», entusiasmo de que não compartilhamos, devido às complicações que acarreta.

Para garantia dos direitos de autores de obras literárias, em matéria de contrato de edição se estabelece a obrigação de numerar os exemplares bem como se dá ao autor a faculdade de controlar a venda (art. 65).

Em matéria de controle das representações e execuções públicas se estabelece, em forma indubitável, a obrigação dos usuários apresentarem à polícia a permissão do autor nas formas indicadas pela lei (art. 73 - inciso 2). 
A alienação da obra plástica, salvo pacto em contrário, não autoriza o adquirente a reproduzí-la ou exibi-la em público (art. 80).

São de interesse jurídico e respondem a conceitos de justiça, fundados no princípio de que ninguém pode enriquecer à custa de outrem sem a devida compensação a este, os chamados «direitos de arena» (art. 100), e os relativos à reprodução ou difusão pública de espetáculos esportivos e de operações cirúrgicas, art. 90. Trata-se de direitos que denomina «afins» para distinguí-los dos que chama «conexos» à industriais e comerciais).

As disposições do capitulo referente à obra cinematográfica são aplicáveis às obras produzidas por qualquer outro processo análago à cinematographia (art. 91). Esta solução resolve o problema relativo às - inadequadamente chamadas - obras «televisuais».

A nova lei brasileira consagra o reconhecimento da necessária função que cumprem as associações de autores (título VI), se bem que não esteja de acordo com as soluções, sobre alguns aspectos, do regime de tais associações.

A criação do Conselho Nacional de Direito Autoral (art. 116 e seguintes) de marcada tendência intervencionista, tem aspectos positivos. Assim, parece-lhe excelente idéia a criação do «Fundo de Direito do Autor», tal como a do «Centro Brasileiro de Informações» sobre Direitos Autorais.

Aborda, em seguida, os aspectos a examinar com espírito crítico.

A filosofia que inspira a nova lei, nem sempre levaria em conta a origem histórica dos direitos de autor e sua formação intuitiva para que seja um «direito de autor para os autores», destinado a estimular os valores do espírito, e sempre buscando que os criadores intelectuais obtenham as compensações de que lhes correspondem.

Esta filosofia se evidencia em aspectos que não são meramente terminológicos ao se querer estender o conceito de titular de direitos de autores a que não é senão industrial e comerciante.

A lei acolhe generosamente os «direitos afins» aos direitos de autor (como são os dos intérpretes e artistas executantes); e a outros direitos chamados «conexos» (direitos de natureza industrial e comercial) que se vêm introduzindo no direito internacional (Convenção de Roma de 1961 e em algumas legislações nacionais).

Acha que, para manter o paralelismo com a Convenção de Roma de 1961, a matéria relativa a proteção dos artistas intérpretes ou executantes, dos produtores de fonogramas e dos organismos de radiodifusão (direitos conexos), deveria desenvolver-se nas legislações nacionais numa lei independente, e não no contexto da lei sobre direitos de autor, ponto de vista do qual discordamos.

Mas a legislação brasileira vai mais longe que a Convenção de Roma, pois reconhece aos titulares de «direitos conexos» - que, de 
qualquer forma, são direitos secundários montados sobre o direito de autor - faculdades que, eventualmente, podem interferir no exercício daquelas que são próprias dos autores, ao outorgar ao produtor de fonogramas o direito de autorizar ou proibir-lhes a reprodução, direta ou indireta, a transmissão e a retransmissão por empresa de radiodifusão, bem como a execução pública a realizar-se por qualquer meio.

$\mathrm{O}$ art. 99 assegura direitos análogos às empresas de radiodifusão. Considera em parte inaceitáveis as soluções relativas à questão das associações de autores frente às necessidades da administração coletiva dos repertórios.

A solução do art. 104, primeira parte, seria perfeita, ao estabelecer que: «Com o ato de filiação as associações se tornam mandatárias de seus associados para a prática de todos os atos necessários à defesa judicial ou extrajudicial de seus direitos autorais, bem como para sua cobrança». Mas tal solução é desvirtuada de forma funesta, em razão do disposto na segunda parte do mesmo artigo (parágrafo único), ao estabelecer que: «sem prejuízo desse mandato, os titulares de direitos autorais poderão praticar pessoalmente os atos referidos neste artigo».

Contratar à margem de sua associação significa, geralmente, deixar indefeso o autor frente a negociações leoninas (ainda que às vezes, sob formas enganosas), e o enfraquecimento das sociedades. A solução deve consistir em exclusividade, para as sociedades, na gerência dos direitos que administram. Isso não importa na obrigatoriedade da filiação, o que poderia ser considerado contrário à liberdade de associação. Mas nada impede que o Estado converta as sociedades nas únicas intermediárias na arrecadação dos direitos de autor, delegando-lhes, em razão do interesse público, os poderes correspondentes, para esse fim.

O severo intervencionismo estatal, a que a lei brasileira submete, a seu ver as sociedades de autores, estaria plenamente justificado se a elas fossem dadas a figura jurídica e os poderes que se acaba de indicar.

Outros aspectos da nova lei, nessa matéria, são os que se referem à criação de um «Bureau» central comum de percepção e arrecadação dos direitos de execução pública (art. 115), para evitar a confusão que representa a existência de várias sociedades tratando receber direitos de autor por diferentes repertórios. Como simples hipótese isto o leva a pensar que em futuro não distante, se chegará à fusão das diversas sociedades numa única, na função de intermediário, com fortes poderes outorgados pelo Estado (solução SADAIC da Argentina).

A lei cria um Conselho Nacional de Direito Autoral, com amplos e diversificados poderes, em matéria de fiscalização, promoção e assistência na matéria. Assim, pelo art. $117, \mathrm{n}^{0} \mathrm{IV}$ está autorizado a fixar normas destinadas à unificação dos preços e sistemas de cobrança e distribuição de direitos autorais. 
Entre os aspectos que merecem sincero aplauso, figura a criação de um Fundo de Direito Autoral para fins de estímulo e promoção, bem como um centro brasileiro de informações sobre direitos de autor, que supõe deverá funcionar em coordenação com o centro internacional criado no seio da UNESCO.

Em matéria de «domínio público remunerado» - instituição justificada em muitos sentidos, - a nova lei consagra uma solução totalmente inadmissivel, e contrária a liberdade da cultura. Com efeito o o art. 93 dispõe que «a utilização por qualquer forma os processo que não seja livre, (?) de obras intelectuais pertencentes ao domínio público, depende de autorização do Conselho Nacional de Direito Autoral. Se a utilização visar lucro deverá ser recolhida ao Conselho Nacional de Direito Autoral uma importância correspondente a $50 \%$ do que caberia ao autor da obra, salvo se se destinar a fins didáticos, casos em que essa percentagem se reduziria a dez por cento.

«Não se trata de um erro de imprensa, ou de interpretação, pois o conceito se repete no art. 120 quando se inclui entre os recursos que integrarão o Fundo do Direito de Autor (parágrafo II): o produto da autorização para a utilização de obras pertencentes ao domínio público», como um desses recursos.

«Em nenhm caso deve a utilização depender da permissão governamental, pois, em caso contrário, se estaria criando um clima de «cultura dirigida». $E$ diferente exigir o pagamento de uma tarifa para cada utilização de obras intelectuais, mas estabelecidas livremente (Ver nossa obra «O domínio público remunerado em matéria de uso de obras intelectuais» Ed. Fundo Nacional das Artes, Buenos Aires, 1970, ou a monografia sobre o mesmo tema na revista «П Diritto de Autore», Roma, 1972). Em se tratando de um simples erro de redação caberia o esclarecimento correspondente pela via legislativa.»

\section{Aponta a ausência de uma matéria fundamental:}

«Para estar em consonância com a evolução social que caracteriza o mundo de hoje e proteger o autor contra abusos e espoliações, não é bastante reconhecer-lhe os direitos morais e declará-los inalienáveis e imprescritíveis. É também necessária uma legislação intuitiva, no aspecto econômico; protetora do autor diante de sua possivel inexperiência, sua debilidade econômica ou equivocação.

Exemplar é, nesse sentido, a lei da Alemanha Federal de 1965, que em sua Seção V sobre «Relações em matéria de direito do autor», busca proteger o autor, também no terreno econômico, salvo na esfera hereditária ou testamentária, o direito de autor não pode ser cedido (arts. 28 e 29). Unicamente podem ser concedidos direitos de aproveitamento e, ainda assim, os gastos a ele referentes, estão limitados e condicionados, mediante revisão de contratos de manifesta desigualdade, ou quando ocorre alteração das circunstâncias levadas em conta ao ser fornecido inicialmente o convênio; e ainda a caducidade por não exercício pelo usuário, etc. (arts. 31 e seguintes).» 
Esta matéria cuja ausência adverte como significativa na nova lei brasileira de 1973.

\section{A Comissão Revisora da Lei no $\mathbf{5 . 9 8 8} / \mathbf{7 3}$.}

Pela Portaria $\mathrm{n}^{\circ}$ 11, de 06-06-1984 foi constituída Comissão, integrada pelos Conselheiros Antônio Chaves, Dirceu de Oliveira e Silva, Henry Jessen, Cleto de Assis e Manoel Joaquim Pereira dos Santos para, sob a Presidência do primeiro proceder a revisão da legislação sobre direitos autorais e a elaboração de propostas que visem o aperfeiçoamento do conteúdo e da redação dos textos legais existentes.

Portaria $\mathrm{n}^{\circ}$ 10, de 31-05-1984 já havia constituído comissão de estudos para analisar as necessidades de alteração do Dec. $n^{\circ} 84.252$, de 28-11-1973, que reorganizou o CNDA e deu outras providências.

Esta última foi revogada pela de $n^{\circ} 16$, de 22-08-1984, que também atribuiu essa tarefa àquela comissão.

A primeira reunião, preliminar, em que foram discutidos aspectos gerais da tarefa e definição de diretrizes e metodologia, teve lugar em data de 11-07-84, em Brasília.

A segunda também ocorreu em Brasília, na sede do CNDA, aos 22-08-1984. Considerando-se as dificuldades, sobretudo financeiras, para a reunião da Comissão, decidiram seus membros dividir os títulos da Lei 5.988 entre si, para um estudo preambular. Ficaram os títulos da Lei 5.988 I, II e III, a cargo do Conselheiro Antônio Chaves; IV, do Cons. de Oliveira e Silva; V. do Cons. Henry Jessen; VI e VII, do Cons. Cleto de Assis, e VIII e IX do Cons. Manoel Joaquim Pereira dos Santos.

Na terceira, que teve lugar no dia 27-09-1984,, o Presidente submeteu ao exame dos demais componentes da Comissão as 57 sugestões oferecidas por vários interessados, tendo sido incorporadas as que pareceram procedentes.

Minucioso trabalho realizado em conjunto pelos Conselheiros Dirceu de Oliveira e Silva e Henry Jessen permitiu a análise, dispositivo por dispositivo dos primeiros 81 artigos propostos, que, com ou sem modificação de redação, já puderam ser analisados na quarta reunião, realizada em data de 27-02-85, em São Paulo.

Defronta-se, no entanto, a Comissão com alguns problemas que considera indispensável apresentar à discussão pública, principalmente neste auspicioso período da vida nacional, em que a Nação é devolvida, depois de 21 anos, à sua tradição democrática, em que o Governo - temos todos a mais absoluta certeza - dará às atividades culturais e artísticas a devida atenção, não podendo nestas condições faltar com o seu apoio à política de aperfeiçoamento do direito de autor.

O primeiro deles parece aos olhos da Comissão ser o que diz respeito ao sistema do registro e depósito, que assume, dia a dia, fundamental importância não só no âmbito nacional, como no internacional. 
Ele está passando, sob os nossos olhos, por uma transformação radical: está deixando, pouco a pouco, de constituir um mero formalismo, uma simples garantia, entre nós, da proteção do direito do autor.

Irá corresponder, cada vez mais, a necessidade de saciar uma verdadeira "fome» de informações de quantos tenham interesse em saber quais são as obras disponíveis para utilização com finalidades econômicas, quem e quantos são os seus titulares, onde podem ser localizados, qual o prazo de proteção com que ainda contam, etc. etc.

Devemos estar aparelhados para, dentro de alguns poucos anos, respondermos, pelos telefones, à indagação que nos venha da Austrália ou do Egito, da possibilidade de se filmar um romance de Jorge Amado, de se publicar um conto de Quintana ou uma poesia de Drummond de Andrade, começando a pensar na montagem de uma estrutura eletrônica que vá desde já possibilitando a coleta de dados continuamente mutáveis, mas que é necessário implantar.

$\mathrm{E}$ isto evidentemente não poderá ocorrer enquanto tivermos uma multiplicidade de registros de muito superior à que resulta da Lei $\mathrm{n}^{\circ}$ 5.988, em diferentes pontos do País: na Biblioteca Nacional, escritos e impressos em geral; na Escola de Música da Universidade Federal do Rio de Janeiro, de composições musicais; Na Escola de Belas Artes da Universidade Federal do Rio de Janeiro, de desenhos, fotografias, etc.; no Conselho Nacional de Cinema, de obras cinematográficas e análogas; no Conselho Federal de Engenharia, Arquitetura e Agronomia, de planos, projetos, etc., e no próprio CNDA de obras que não se enquadrem nas entidades nomeadas.

O pior é que, fomentando pedidos desnecessários, quando não injustificados e abusivos, numa disposição demagógica que precisa ser corrigida, admite o art. 10 da gratuidade não apenas do registro da obra intelectual, como do seu respectivo translado.

Submetemos à apreciação da Comissão mais os seguintes princípios orientadores para a atualização da legislação básica:

1. Retirar do contexto da lei toda referência ao intuito de lucro.

2. Qualquer comunicação de uma obra, pelo rádio ou pela TV, a um «público» ulterior, deve proporcionar uma remuneração aos autores e artistas, em harmonia com a potencialidade da difusão.

3. Deve ser objeto de regulamentação mais rigorosa a cessão, proibindo-se a indiscriminada de todos os direitos e estabelecendo-se, mesmo contra a vontade do cedente, a reserva de uma percentagem minima a seu favor.

4. Revogação da Lei 7.123 , de 12-09-1983, que aboliu o domínio público remunerado, beneficiando exclusivamente os empresários, em detrimento dos autores e do público.

5. Incorporação dos preceitos constantes de projeto de lei já aprovado pelo CNDA, estabelecendo remuneração de natureza autoral 
sobre as fitas virgens para cassetes, videocassetes e similares, destinadas a cópia privada.

6. Critério análogo deve ser firmado com relação a reprografia de obras impressas.

7. Estimular a redução da multiplicidade de associações arrecadadoras e distribuidoras em matéria de execução musical e fomentar a criação de outras que cubram importantes segmentos que ficam ao desamparo.

8. A própria denominação - Conselho Nacional de Direito Autoral - indica que suas atividades não podem restringir-se, como hoje ocorre, exclusivamente à área da música popular, mas ampliar-se de modo a abrangerem toda manifestação intelectual e artística, que deve ser incentivada e desvelada como uma das mais nobres manifestações da inteligência e da sensibilidade humanas.

Além dessas providências de caráter propriamente legal, reco. menda-se ainda três pontos fundamentais.

E necessário:

Incrementar, nas Universidades e nos cursos superiores de Arte e de Música, o ensino do Direito de Autor, como recomendam os Congressos internacionais, entre eles o da INTERGU e do IIDA, em Santiago do Chile, de 30 de outubro a 04-11-1983, para que haja uma rnelhor compreensão da matéria.

Fomentar e disciplinar o aproveitamento do talento brasileiro além fronteiras.

Estabelecer uma maior participação de peritos nas grandes reuniões internacionais. A pretexto de falta de verbas, o Brasil é a eterna cadeira vazia, como ocorreu na reunião entre outras de dezembro de 1984, em Paris, que cuidou da proteção internacional do folclore, onde, estiveram presentes numerosos países de menor potencial econômico e cultural do que o nosso, que brilhou. .. pela ausência.

\section{Bibliografia aproveitada:}

BarboSA, Milton Sebastião - Projeto de Código do Direito de Autor e Direitos Conexos e respectiva Justificacão, Dírio Oficial, suplemento ao no 113, de 16-06-1967, 39 págs.

CHAVES, Antônio - Direito Autoral de Radiodifusão, S. Paulo, Ed. Rev. dos Tribunais, 1952, págs. 15-27.

GONCALVES, Luiz da Cunha - Tratado de Direlto Civil, S. Paulo, Limonad, 2a ed., vol. IV, I, sem data, págs. 28-36.

HAMMES, Bruno Jorge - O Direito do Autor. Algumas Notas Hístóricas Estudos Juridicos, Universidade do Vale do Rio dos Sinos, vol. $\mathrm{X}$, no 27, 1980, págs. $69-80$.

LINS, Osman - Direitos autorais: breve retrospecto, «O Estado de S. Paulo», Suplemento Literário, 15-03-1969. 